\title{
Nanocomposites Fe/Activated Carbon/PVA for Microwave Absorber: Synthesis and Characterization
}

\author{
Bualkar Abdullah, Sultan Ilyas, and Dahlang Tahir (D) \\ Department of Physics, Hasanuddin University, Makassar 90245, Indonesia \\ Correspondence should be addressed to Dahlang Tahir; dtahir@fmipa.unhas.ac.id
}

Received 4 February 2018; Revised 3 April 2018; Accepted 21 May 2018; Published 8 July 2018

Academic Editor: Yasuhiko Hayashi

Copyright ( 2018 Bualkar Abdullah et al. This is an open access article distributed under the Creative Commons Attribution License, which permits unrestricted use, distribution, and reproduction in any medium, provided the original work is properly cited.

\begin{abstract}
Nanocomposites, activated carbon/polyvinyl alcohol (AC/PVA) filled with $\mathrm{Fe}$ to form Fe/AC/PVA, were characterized by using X-ray fluorescence (XRF), X-ray diffraction (XRD), Fourier transform infrared (FTIR), and vector network analyzer (VNA). The crystal orientations from $\mathrm{Fe}$ are (104), (110), and (200) and the bonding formations of $\mathrm{AC}$ are $\mathrm{O}-\mathrm{H}, \mathrm{C}-\mathrm{H}$, and $\mathrm{C}=\mathrm{C}$ show existence in nanocomposites, which may be due to the Fe that has been filled the pore of $\mathrm{AC}$ via a chemical bond. $20 \% \mathrm{AC}$ ( $3 \mathrm{~mm}$ in thickness) in nanocomposites shows higher performance absorption for C-band $(4.65 \mathrm{GHz})$ with maximum reflection loss of $-32.5 \mathrm{~dB}$.
\end{abstract}

\section{Introduction}

Development of modern technology in electronic system and telecommunications has greatly increased the demand for electronic devices using $1-5 \mathrm{GHz}$ range microwave radiation, which is resulting in serious electromagnetic interference (EMI) problems [1-6]. EMI causes device malfunctions, generates false images, and reduces the performance of the system-to-system coupling to a radar system. This has led to a search and creates a new material for electromagnetic (EM) wave absorber with the capability to prevent EMI.

Electromagnetic wave absorber used dielectric materials and magnetic materials that can prevent EMI. Dielectric materials include conducting polymers, carbon, and silicon carbide, which are more lightweight and have high-temperature stability but have poor absorption electromagnetic waves. Magnetic materials such as ferrite and metallic magnetic materials can be used as an electromagnetic absorber; however, the problem of magnetic materials is high conductivity and magnetization induced by electromagnetic waves [7-12]. For these reasons, it is better to use small particle carbonyl iron.

Iron $(\mathrm{Fe})$ and carbon are commonly used as absorber electromagnetic waves [13-16]. Recently, many studies reported on composites such as organic metals Fe/Zn/carbon [1], Fe/carbon [2], and nanocomposite of Co/carbon [3] with reflection loss up to $-29.5 \mathrm{~dB}$. Reference [17] was reported to nanocomposite $\mathrm{RGO} / \mathrm{Fe}_{3} \mathrm{O}_{4}$ with additional $\mathrm{ZnO}$ that shows EM wave absorption properties the $\mathrm{RGO} / \mathrm{Fe}_{3} \mathrm{O}_{4}$ up to $-57 \mathrm{~dB}$ at $13.5 \mathrm{GHz}$ and the thickness of $2.0 \mathrm{~nm}$. $\mathrm{ZnO}$ is attributed to the interfacial polarization and impedance matching but increases the dielectric losses at higher frequency and magnetic losses at lower frequency due to the unstable bonding at surface composition or valence state. The absorption properties are great challenges which were usually depended on the natural resonance and the eddy current effect of the unstable bonding at the surface composition or valence states. Although there are some works on carbon-based and iron-based materials for the electromagnetic wave absorption, it is still a significant challenge by using the pore of $\mathrm{AC}$ as a trap of magnetic particles to achieve high performance by stabilized bonding with surface composition or valence states. By this method, the surface composition or valence state will be more stable in reducing the natural resonance and eddy current effect to improve reflection loss. PVA was used to form continuous network polymer to produce thinner thickness and lighter weight. As long as we know, there is no study reported for absorber materials by 
utilizing the pore of activated carbon (AC) as a trap of magnetic particles for stabilizing bonding at the surface composition or valence state.

In this study, PVA could improve the permeability by interfacial adhesion forming a continuous network by utilization of the pore of $\mathrm{AC}$ as a trap of metallic magnetic particle (Fe) for stabilizing bonding at surface composition or valence state and will raise polarization relaxation to increase the permittivity [5-10]. The proposed method in the fabrication of nanocomposite $\mathrm{Fe} / \mathrm{AC} / \mathrm{PVA}$ materials in this study is relatively easy-to-handle and economic; the method can be seen clearly in Figure 1.

The nanocomposite materials were characterized by using various techniques (XRD, FTIR, and XRF) to establish the relationship of composition and structural and chemical properties to the electromagnetic wave absorption performance. Electromagnetic wave absorber performance was measured by using vector network analyzer (VNA).

\section{Experiments}

2.1. Materials. PVA (polyvinyl alcohol) purity $99.5 \%$ was purchased from Merck. Iron powder $(\mathrm{Fe})$ was purchased from Sigma-Aldrich in a form of carbonyl-iron powder, low in magnesium and manganese compounds, $\geq 99.5 \%$, resistivity $9.71 \mu \Omega \mathrm{cm}$, impurities $\leq 0.01 \%$ total nitrogen $(\mathrm{N})$, and grain size 5-9 $\mu \mathrm{m}$. Activated carbon (AC) was supplied from the local company PT. Cahaya Indo Abadi in Indonesia with a size of an average diameter $<10 \mu \mathrm{m}$, purity $>95 \%$, and surface area $>240 \mathrm{~m} / \mathrm{g}$.

2.2. Sample Preparation. Activated carbon (AC) was crushed into powder by using a mortar and sieved with 200 meshes. For homogeneous nanocomposites, the Fe was mixed with AC by Retsch MM for 30 minutes at a frequency $10 \mathrm{~Hz}$, which was controlled by XRF. The final mass of each sample is 15 grams in nanocomposite that consists of $10 \%, 20 \%$, and $25 \%$ of $\mathrm{AC}$.

2.3. Compaction Process. The samples were added $5 \mathrm{ml}$ in $2 \%$ concentration of PVA for each sample and poured into the beaker. Samples were stirred at $50^{\circ} \mathrm{C}$ for 30 minutes by using a magnetic stirrer to obtain slurry form. The samples were pelleted (thickness $2 \mathrm{~mm}, 3 \mathrm{~mm}$, and $4 \mathrm{~mm}$ ) by using hydraulic compactor at a pressure of $50 \mathrm{kPa}$ and then were cooled naturally for 5-7 minutes. Samples were annealed in a furnace at $80^{\circ} \mathrm{C}$ for 5 hours. Figure 1 shows the fabrication processes of nanocomposites for the microwave absorber.

2.4. Characterization. Crystallite size of the samples was determined from the X-ray diffraction (XRD) data. Spectra were collected on XRD spectroscopy (Shimadzu 7000) with $\mathrm{CuK} \alpha$ radiation $(\lambda=1.5405 \AA)$ over the angular range $15^{\circ} \leq 2 \theta \leq 80^{\circ}$, operating at $30 \mathrm{kV}$ and $10 \mathrm{~mA}$. The elemental composition of the samples was determined by X-ray fluorescence (XRF) spectroscopy, a Thermo ARL QUANT'X EDXRF model. Fourier transform infrared (FTIR) spectroscopy was carried out on a IRPrestige-21 FTIR spectrometer (Shimadzu Corp.) equipped with a bright ceramic light source, a KBr beamsplitter, and a deuterated triglycine sulfate doped with L-alanine (DLATGS) detector. The measurements of the samples were collected over the range of $4000-600 \mathrm{~cm}^{-1}$ and 16 coadded scans. All spectra of FTIR were in transmittance units. Electromagnetic wave absorber performance was measured by using vector network analyzer (VNA) (Rohde \& Schwarz, ZVHB) with the frequency range from $2.5 \mathrm{GHz}$ to $8 \mathrm{GHz}$.

\section{Results and Discussion}

Table 1 shows the chemical composition of iron powder (Fe), AC, and nanocomposites determined by using XRF spectroscopy. The amount of chemical oxide for pure AC is $35.47 \%, 38.41 \%, 12.18 \%, 6.98 \%$, and $2.36 \%$, respectively, for $\mathrm{Fe}_{2} \mathrm{O}_{3}, \mathrm{SiO}_{2}, \mathrm{~K}_{2} \mathrm{O}, \mathrm{CaO}$, and $\mathrm{TiO}_{2}$. Nanocomposites show Fe increase with the increasing amount $\mathrm{AC}$, as we predict due to the highest amount of $\mathrm{Fe}_{2} \mathrm{O}_{3}$ in pure AC. Chemical composition in Table 1 indicated homogenates of nanocomposite in this study.

For nanocomposites, the aspect ratios of PVA as a matrix for composites (AC and $\mathrm{Fe}$ ) and $\mathrm{AC}$ as a second matrix for $\mathrm{Fe}$ as fillers are important parameters and offer a large flexibility for design and property control. Nanocomposite with $\sim 10 \%$ $\mathrm{AC}$ appears the element $\mathrm{MgO}$ probably comes from the PVA. AC is more attractive bonding due to the surface area, so for low AC content, not all Fe atoms filled the pore of $\mathrm{AC}$ and formed covalent bonding; by adding the PVA, some of these Fe atoms outside the pore of AC by interfacial adhesion form small area continuous network. For $>10 \%$ AC, the amount of $\mathrm{MgO}$ decreases with increasing the amount of $\mathrm{AC}$ that may due to the amount of Fe particles that has enough filled the pore of AC and by using PVA as an interfacial adhesion forming uniform and strong continuous network bonding with $\mathrm{AC}$ and Fe particles. Figure 2 shows schematic illustrations of the pore of AC filled with Fe particles and PVA as a matrix for composites to form interfacial adhesion which could improve chemical bonding between $\mathrm{Fe}$ and $\mathrm{AC}$ and also supporting to reduce conductivity $[12,13]$. The interfacial adhesion between matrix and filler in nanocomposites Fe/AC/PVA is also a great influence on the properties of composites: absorption capacity and structural properties. The continuous network bonding is beneficial to EMI shielding of nanocomposite as reported by Hoang A. S. (2011) [18] and Kuester et al. (2016) [19].

Structural properties from XRD spectra for $2 \theta$ from $10^{\circ}$ to $65^{\circ}$ can be seen clearly in Figure 3, for pure Fe, for pure AC, and nanocomposites for $10 \%, 20 \%$, and $25 \%$ of AC. Several crystal orientations appear for pure Fe are (104), (110), and (200). For nanocomposites in Figure 3, the peaks are small shifted from pure Fe position to lower $2 \theta$ positions due to bonding formation changed in the composites $[1,8]$. Contribution from $\mathrm{Fe}$ and $\mathrm{AC}$ in nanocomposites can be seen in Figure 3 by start symbol and solid circle symbol, respectively. The broad diffraction peak of $18^{\circ}$ to $28^{\circ}$ indicated the disordered carbon form which is a good characteristic to store electrical energy and may correspond with function of the pore of AC as a trap Fe particles $[1,9,15]$. PVA was used as interfacial adhesion which could improve chemical 


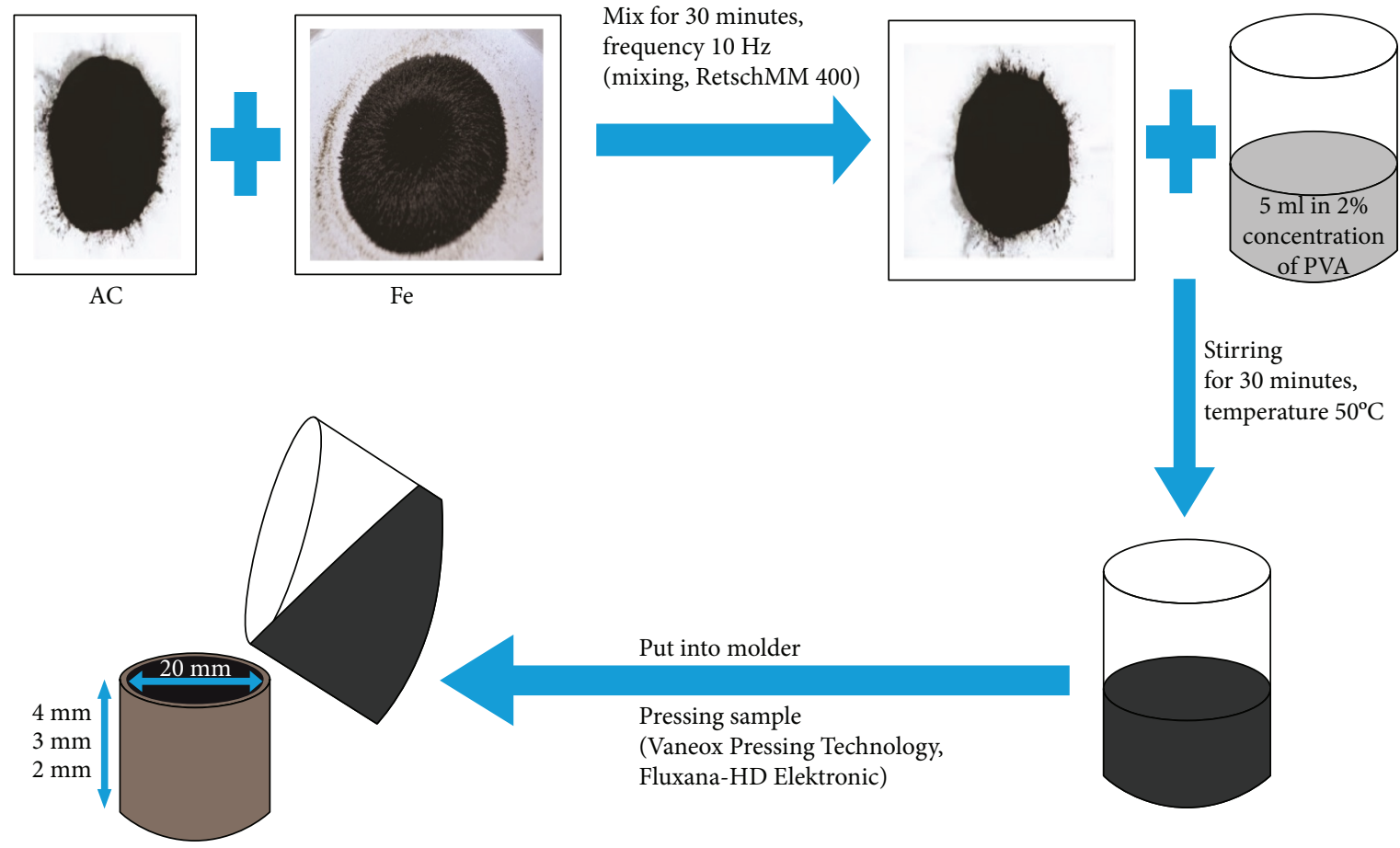

FIGURE 1: Fabrication processes of Fe/AC/PVA nanocomposites for electromagnetic wave absorber.

TAble 1: Chemical compounds for pure $\mathrm{Fe}, \mathrm{AC}$, and nanocomposites determined by XRF spectroscopy. The total amount of chemical compounds is $100 \%$ with loss on ignition (LOI) by XRF spectroscopy which is up to $3.9 \%$.

\begin{tabular}{lccccc}
\hline $\begin{array}{l}\text { Chemical } \\
\text { compound }\end{array}$ & $\mathrm{Fe}$ & $\begin{array}{l}\text { Sample (composition (\%)) } \\
\text { Activated } \\
\text { carbon (AC) }\end{array}$ & $10 \% \mathrm{AC}$ & $20 \% \mathrm{AC}$ & $25 \% \mathrm{AC}$ \\
\hline $\mathrm{Fe}_{2} \mathrm{O}_{3}$ & 97.98 & 35.47 & 82.87 & 88.28 & 89.89 \\
$\mathrm{TiO}_{2}$ & 0.67 & 2.36 & 1.71 & 2.15 & 2.51 \\
$\mathrm{MnO}$ & 0.56 & 0.749 & 1.27 & 1.57 & 1.59 \\
$\mathrm{CaO}$ & 0.297 & 6.98 & 0.526 & 0.709 & 0.85 \\
$\mathrm{P}_{2} \mathrm{O}_{5}$ & 0.356 & - & 0.27 & - & - \\
$\mathrm{K}_{2} \mathrm{O}$ & - & 12.18 & 0.526 & 1.40 & 1.91 \\
$\mathrm{SiO}_{2}$ & - & 38.41 & 4.12 & 5.02 & 5.15 \\
$\mathrm{MgO}^{2}$ & - & - & 8.73 & 1.27 & 0.11 \\
\hline
\end{tabular}

bonding with $\mathrm{AC}$ and $\mathrm{Fe}$ and will raise polarization relaxation to increase the permittivity [19-24].

We determined crystallite sizes from the XRD spectra by using Scherrer equation with the average crystallite sizes for each absorber, which are $15 \mathrm{~nm}$ for $10 \%$ AC, $24 \mathrm{~nm}$ for $20 \%$ $\mathrm{AC}$, and $12 \mathrm{~nm}$ for $25 \% \mathrm{AC}$ in nanocomposites Fe/AC/PVA.

FTIR spectra as shown in Figure 4 were recorded in the wavelength range of 4000 to $500 \mathrm{~cm}^{-1}$. The FTIR results for $\mathrm{Fe}$ and $\mathrm{AC}$ prove that there is the same type of bond from the functional group. The intensity of bonding formation from $\mathrm{Fe}$ is increased with increasing the amount of $\mathrm{AC}$ in the nanocomposites as confirmed by the XRF results. In Figure 4(a), Fe shows the presence of Fe-O vibration at $583.6 \mathrm{~cm}^{-1}, \mathrm{C}-\mathrm{N}$ amine bonds at $1028.06 \mathrm{~cm}^{-}, \mathrm{C}-\mathrm{OH}$ bonds at $1554.63 \mathrm{~cm}^{-1}$, and $\mathrm{O}-\mathrm{H}$ bond at $3439.04 \mathrm{~cm}^{-1}$. In
Figure 4(b), AC shows the small $\mathrm{Fe}-\mathrm{O}$ vibration bonds at $551.64 \mathrm{~cm}^{-1}$ and $\mathrm{C}-\mathrm{N}$ amine shows the strongest peak at $1023.47 \mathrm{~cm}^{-1}$. C-H vibration bond appears at $2879.72 \mathrm{~cm}^{-1}$ and the $\mathrm{C}=\mathrm{C}$ aromatic ring is at $1681.93 \mathrm{~cm}^{-1}$. The broad absorption peak for $\mathrm{O}-\mathrm{H}$ bond is at $2526.75 \mathrm{~cm}^{-1}$ and the small peak at $3394.72 \mathrm{~cm}^{-1}$. For nanocomposites in Figures 4(c)-4(e), the bonding formation is influenced by the $\mathrm{Fe}$ and $\mathrm{AC}$ as can be seen clearly for $\mathrm{O}-\mathrm{H}, \mathrm{C}-\mathrm{N}, \mathrm{C}=\mathrm{C}$, and $\mathrm{Fe}-\mathrm{O}$ intensities, which are increased with increasing the amount of AC. Bonding formation of $\mathrm{O}-\mathrm{H}$ that was shifted from $3439.04 \mathrm{~cm}^{-1}(\mathrm{Fe})$ to $3392 \mathrm{~cm}^{-1}(20 \% \mathrm{AC})$ and Fe-O from $583.6 \mathrm{~cm}^{-1}$ (Fe) to $586.4 \mathrm{~cm}^{-1}(20 \% \mathrm{AC})$ may correspond to functional of the pore of $\mathrm{AC}$ as a trap that has been filled with $\mathrm{Fe}$ particle via covalent bond, which is similar with that of reported by Zhang et al. (2017) [23]. The active functional group (C-N) at the surface will improve the dispersion of nanocomposites in PVA; thereby, $\mathrm{Fe} / \mathrm{AC} / \mathrm{PVA}$ possess resulting better magnetic network which provided multiple reflections and offered sufficient transmission path for PVA network to attenuate EM wave $[23,24]$. AC was the dielectric loss of Fe/AC/PVA network, and the presence of PVA could further increase the dielectric loss due to dipole relaxation and interface relaxation [18-23]. AC was facilitating charge transfer and was removing the effect of natural resonance due to the strong bonding at the surface composition or valence state which increased the magnetic loss of the nanocomposites.

In order to find an optimum thickness of the absorber needed to measure the maximum reflection loss in a broad frequency region, the reflection loss values in different thickness were measured in this study. The ability of absorption has been measured by using VNA for the frequency range $2.5 \mathrm{GHz}-8 \mathrm{GHz}$ as shown in Figure 5. The value of reflection 

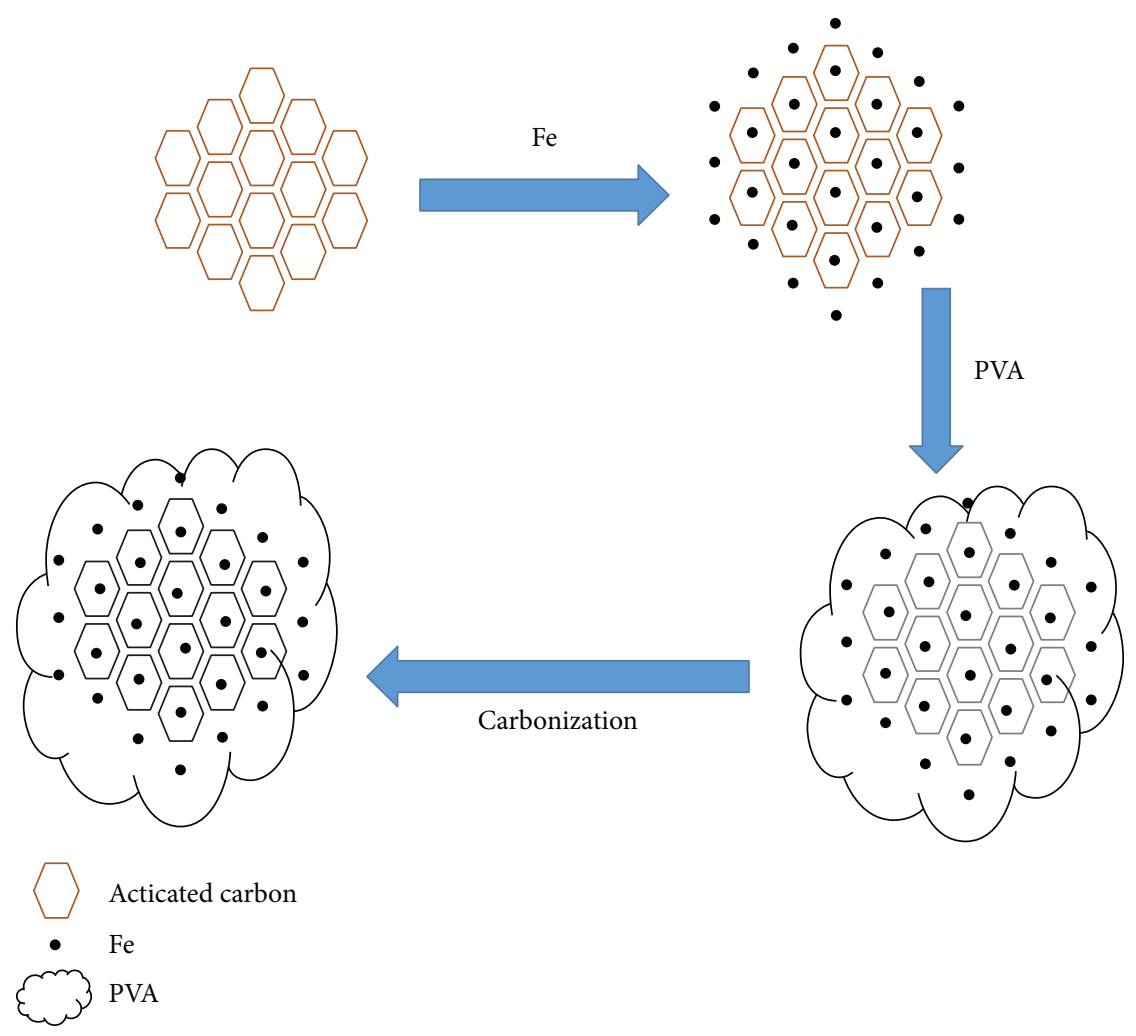

Figure 2: Schematic illustrations of the pore of AC filled with Fe and bonding formation of PVA.

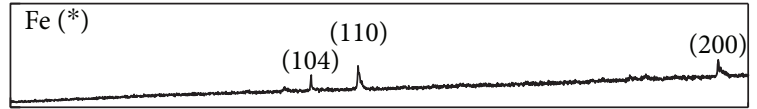

(a)

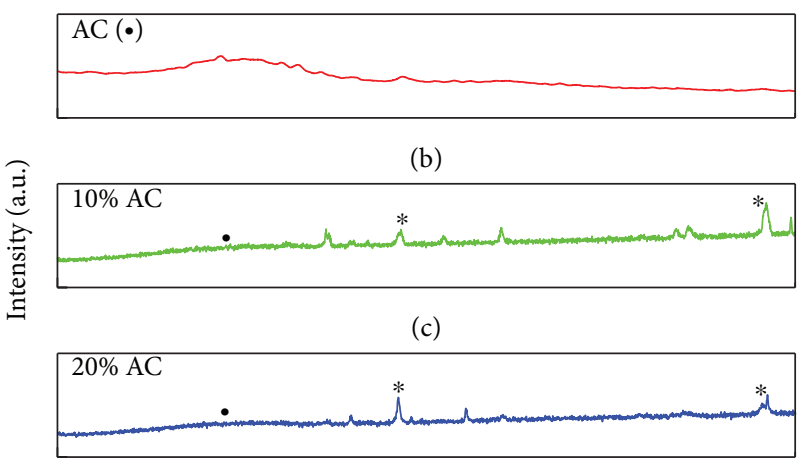

(d)

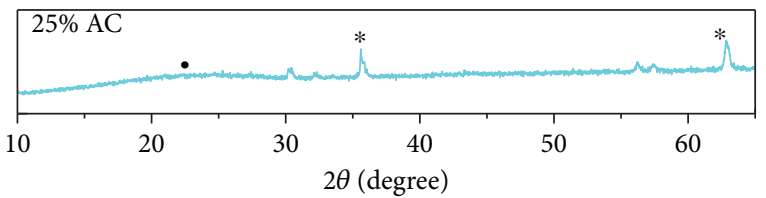

(e)

FIGURE 3: XRD spectra in this study: (a) Fe, (b) AC, (c) 10\% AC, (d) $20 \% \mathrm{AC}$, and (e) $25 \%$ AC. $(*$ indicated the reflection spectra from $\mathrm{Fe}$ and $\bullet$ from AC). loss (RL) is strongly influenced by the amount of the activated carbon and the thickness of each nanocomposite. Figure 5 shows VNA spectra of the RL for each sample and shows the best absorption frequency in the range of C-band from $4.5 \mathrm{GHz}$ to $5 \mathrm{GHz}$. The absorption ability (RL) shows an increase with increasing the thickness of the samples from $2 \mathrm{~mm}$ to $3 \mathrm{~mm}$ and reduces when the thicknesses reach $4 \mathrm{~mm}$. Figure 5 shows that $\mathrm{Fe}$ (for $0 \% \mathrm{AC}$ ) shows 2 peaks at $5.7 \mathrm{GHz}$ and 7. $2 \mathrm{GHz}$ and $\mathrm{RL}$ about $-15 \mathrm{~dB}$ to $-18 \mathrm{~dB}$. The second peak at $7.2 \mathrm{GHz}$ shows the existence of natural resonance due to the unstable surface composition or valence states. For nanocomposites, the natural resonance is not appearing indicated that the pore of $\mathrm{AC}$ was facilitating charge transfer and stabilized the bonding at the surface composition or valence state [17]. 10\% AC shows RL increase from $-17.5 \mathrm{~dB}$ to $-27.5 \mathrm{~dB}$ and decrease to $-20 \mathrm{~dB}$ for thicknesses $2 \mathrm{~mm}, 3 \mathrm{~mm}$, and $4 \mathrm{~mm}$, respectively, similar case for $20 \%$ $\mathrm{AC}$ and $25 \% \mathrm{AC}$ in Figure 5.

Bandwidth frequency corresponding to the reflector loss at $-10 \mathrm{~dB}$ increased from 1.3 to $2.2 \mathrm{GHz}$ as shown in Figure 5 by lines. AC could effectively improve the electromagnetic wave absorbing properties of the nanocomposites at the frequency range of $4.5 \mathrm{GHz}-5 \mathrm{GHz}$. The effect of thickness of nanocomposites to the electromagnetic wave absorption properties in this study can be seen clearly in Table 2.

From RL in this study shows that the highest RL capacity is $-32.5 \mathrm{~dB}$ for sample $20 \% \mathrm{AC}$ with thickness $3 \mathrm{~mm}$ in C-band compared with recent results for RL $-29.5 \mathrm{~dB}$ and $-22.6 \mathrm{~dB}$ reported by Liu Q. et al. (2017) [1] and Qiang R. 


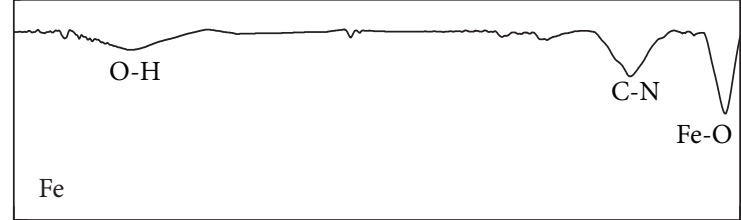

(a)

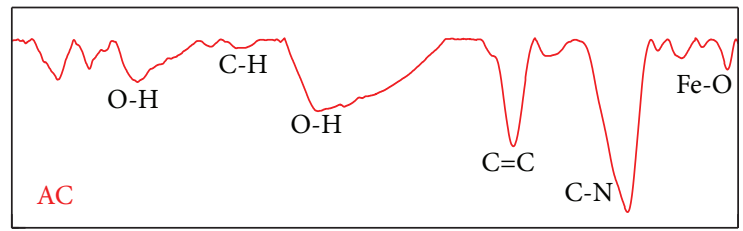

(b)

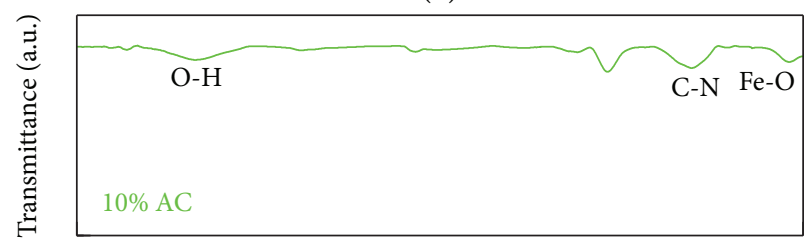

(c)

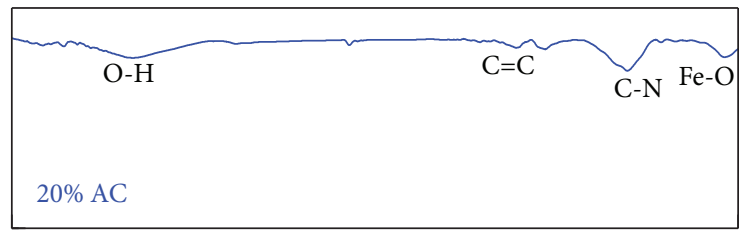

(d)

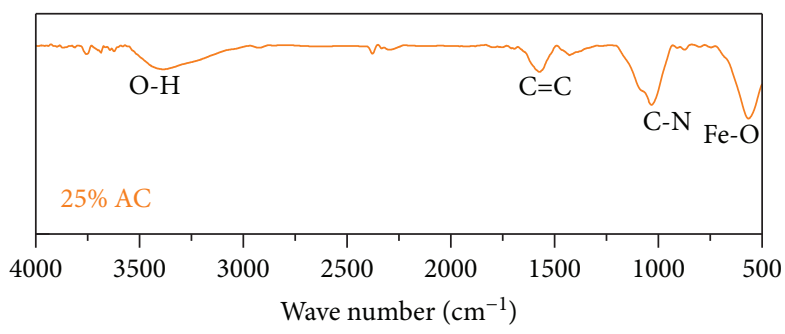

(e)

FIGURE 4: FTIR spectra in this study: (a) Fe, (b) AC, (c) 10\% AC, (d) $20 \% \mathrm{AC}$, and (e) $25 \% \mathrm{AC}$.

et al. (2015) [2], respectively. For all samples with $3 \mathrm{~mm}$ thickness that show high RL may be due to the surface area of AC that has a good ability to store electrical energy and PVA may contribute to the permeability by forming continuous network uniform that makes easy to penetrate the magnetic particle in the nanocomposites which are supporting to reduce natural resonance and conductivity of the magnetic material $(\mathrm{Fe})[1,2,8,15]$. The above results imply that we can get a higher electromagnetic absorption in the range of C-band from $4.5 \mathrm{GHz}-5 \mathrm{GHz}$ by varying the thickness and the content of the $\mathrm{AC}$ in $\mathrm{Fe} / \mathrm{AC} / \mathrm{PVA}$ nanocomposites to meet different demands [21]. In summary, the $\mathrm{AC}$ in the $\mathrm{Fe} / \mathrm{AC} / \mathrm{PVA}$ nanocomposites plays an important role in the electromagnetic wave absorbing performance. However, the detailed effects of the thickness, the bonding mechanism with Fe particles, conductivity of

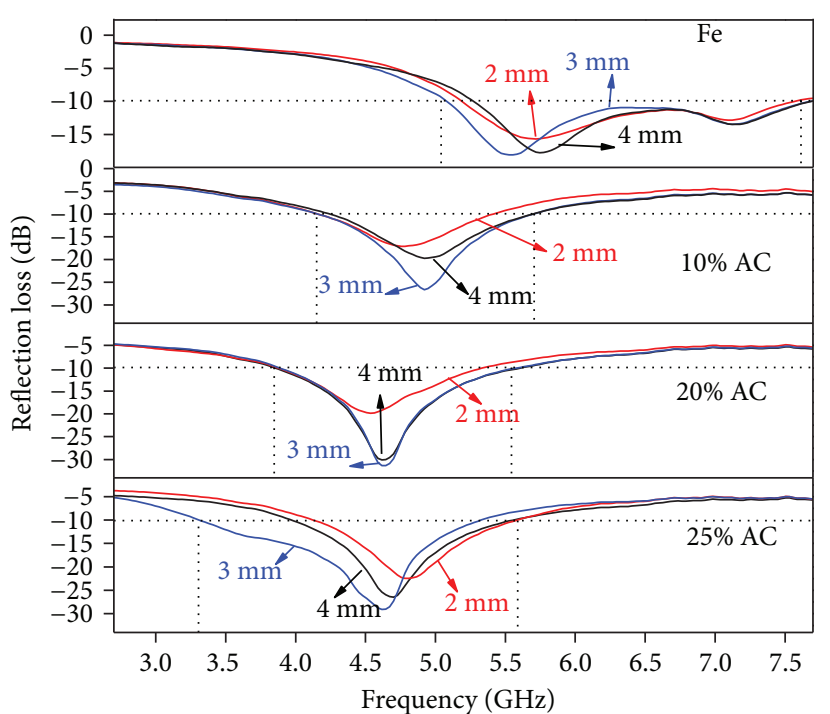

FIGURE 5: Electromagnetic (EM) waves absorbing properties in this study for $0 \% \mathrm{AC}(\mathrm{Fe}), 10 \% \mathrm{AC}, 20 \% \mathrm{AC}$, and $25 \% \mathrm{AC}$ in $\mathrm{Fe} / \mathrm{AC} /$ PVA nanocomposites with different thickness: $2 \mathrm{~mm}, 3 \mathrm{~mm}$, and $4 \mathrm{~mm}$.

TABLE 2: Electromagnetic (EM) wave absorbing properties of $\mathrm{Fe} /$ AC/PVA nanocomposites in this study.

\begin{tabular}{lcccc}
\hline Samples & $\begin{array}{c}\text { Thickness } \\
(\mathrm{mm})\end{array}$ & $\begin{array}{c}\text { Reflection } \\
\text { loss }(\mathrm{dB})\end{array}$ & $\begin{array}{c}\text { Frequency } \\
(\mathrm{GHz})\end{array}$ & $\begin{array}{c}\text { Frequency } \\
\text { bandwidth }(\mathrm{GHz})\end{array}$ \\
\hline \multirow{3}{*}{$\mathrm{Fe}$} & 2 & -15.61 & 5.71 & 2.41 \\
& 3 & -18.02 & 5.52 & 2.58 \\
& 4 & -17.69 & 5.75 & 2.37 \\
\hline \multirow{3}{*}{$10 \% \mathrm{AC}$} & 2 & -17.08 & 4.76 & 1.30 \\
& 3 & -26.61 & 4.92 & 1.56 \\
\hline \multirow{3}{*}{$20 \% \mathrm{AC}$} & 3 & -18.80 & 5.06 & 1.45 \\
& 2 & -19.85 & 4.52 & 1.55 \\
& 4 & -32.50 & 4.65 & 1.76 \\
$25 \% \mathrm{AC}$ & 3 & -31.30 & 4.62 & 1.76 \\
& 4 & -26.07 & 4.62 & 1.46 \\
\hline \multirow{2}{*}{ A } & 2 & -22.48 & 4.78 & 2.20 \\
\hline
\end{tabular}

nanocomposites, and the composition of AC on the electromagnetic wave absorption properties of Fe/AC/PVA nanocomposites still need deeper investigations.

\section{Conclusions}

Fe/AC/PVA nanocomposites were successfully synthesized by simple method utilizing the pore of $\mathrm{AC}$ as a trap of Fe particle and PVA was used to form continuous network with the thicknesses that were varied: $2 \mathrm{~mm}, 3 \mathrm{~mm}$, and $4 \mathrm{~mm}$. Fe has been filled the pore of AC via a chemical bond and shows stabilized bonding at the surface composition or valence state as confirmed by the existence of $\mathrm{O}-\mathrm{H}, \mathrm{C}-\mathrm{H}$, and $\mathrm{C}=\mathrm{C}$ bonding formations in nanocomposites from the FTIR spectra. We demonstrated that Fe/AC/PVA 
nanocomposites have very good electromagnetic wave absorption properties for frequency range of $4-6 \mathrm{GHz}$. The reflection loss value of $\mathrm{Fe} / \mathrm{AC} / \mathrm{PVA}$ nanocomposites for the $20 \% \mathrm{AC}$ and the thickness $3 \mathrm{~mm}$ is $-32.5 \mathrm{~dB}$ which effectively improves the electromagnetic wave absorbing properties for C-band at the frequency of $4.65 \mathrm{GHz}$.

\section{Conflicts of Interest}

The authors declare that they have no conflicts of interest.

\section{Acknowledgments}

The authors thank the Hasanuddin University, Indonesia, by Professorship 2017 program and PBK 2018 program for the financial support.

\section{References}

[1] Q. Liu, X. Liu, H. Feng, H. Shui, and R. Yu, "Metal organic framework-derived $\mathrm{Fe} /$ carbon porous composite with low $\mathrm{Fe}$ content for lightweight and highly efficient electromagnetic wave absorber," Chemical Engineering Journal, vol. 314, pp. 320-327, 2017.

[2] R. Qiang, Y. Du, H. Zhao et al., "Metal organic framework-derived $\mathrm{Fe} / \mathrm{C}$ nanocubes toward efficient microwave absorption," Journal of Materials Chemistry, vol. 3, no. 25, pp. 13426-13434, 2015.

[3] Y. Lu, Y. Wang, H. Li et al., "MOF-derived porous Co/C nanocomposites with excellent electromagnetic wave absorption properties," ACS Applied Materials \& Interfaces, vol. 7, no. 24, pp. 13604-13611, 2015.

[4] J.-L. Lv, S.-R. Zhai, C. Gao, N. Zhou, Q.-D. An, and B. Zhai, "Synthesis of lightweight, hierarchical cabbage-like composites as superior electromagnetic wave absorbent," Chemical Engineering Journal, vol. 289, pp. 261-269, 2016.

[5] S. T. Liu, K. K. Yan, Y. H. Zhang, S. D. Jin, Y. Ye, and X. G. Chen, "Magnesiothermic reduction of rice husk ash for electromagnetic wave adsorption," Journal of Magnetism and Magnetic Materials, vol. 394, pp. 266-273, 2015.

[6] Y. Huang, X. Ding, S. Li, N. Zhang, and J. Wang, "Magnetic reduced graphene oxide nanocomposite as an effective electromagnetic wave absorber and its absorbing mechanism," Ceramics International, vol. 42, no. 15, pp. 17116-17122, 2016.

[7] Q. Q. Ni, G. J. H. Melvin, and T. Natsuki, "Double-layer electromagnetic wave absorber based on barium titanate/ carbon nanotube nanocomposites," Ceramics International, vol. 41, no. 8, pp. 9885-9892, 2015.

[8] J. Kim, S. Lee, and C. Kim, "Comparison study on the effect of carbon nano materials for single-layer microwave absorbers in X-band," Composites Science and Technology, vol. 68, no. 14, pp. 2909-2916, 2008.

[9] S. S. Kim, S. T. Kim, J. M. Ahn, and K. H. Kim, "Magnetic and microwave absorbing properties of $\mathrm{Co}-\mathrm{Fe}$ thin films plated on hollow ceramic microspheres of low density," Journal of Magnetism and Magnetic Materials, vol. 271, no. 1, pp. 39-45, 2004.

[10] X. G. Liu, B. Li, D. Y. Geng et al., "(Fe, Ni)/C nanocapsules for electromagnetic-wave-absorber in the whole Ku-band," Carbon, vol. 47, no. 2, pp. 470-474, 2009.

[11] S. W. Phang, M. Tadokoro, J. Watanabe, and N. Kuramoto, "Synthesis, characterization and microwave absorption property of doped polyaniline nanocomposites containing $\mathrm{TiO}_{2}$ nanoparticles and carbon nanotubes," Synthetic Metals, vol. 158, no. 6, pp. 251-258, 2008.

[12] Y. B. Feng, T. Qiu, and C. Y. Shen, "Absorbing properties and structural design of microwave absorbers based on carbonyl iron and barium ferrite," Journal of Magnetism and Magnetic Materials, vol. 318, no. 1-2, pp. 8-13, 2007.

[13] H. Lin, H. Zhu, H. Guo, and L. Yu, "Investigation of the microwave-absorbing properties of Fe-filled carbon nanotubes," Materials Letters, vol. 61, no. 16, pp. 3547-3550, 2007.

[14] M. R. Meshram, N. K. Agrawal, B. Sinha, and P. S. Misra, "Characterization of M-type barium hexagonal ferrite-based wide band microwave absorber," Journal of Magnetism and Magnetic Materials, vol. 271, no. 2-3, pp. 207-214, 2004.

[15] G. Shen, Z. Xu, and Y. Li, “Absorbing properties and structural design of microwave absorbers based on W-type La-doped ferrite and carbon fiber composites," Journal of Magnetism and Magnetic Materials, vol. 301, no. 2, pp. 325-330, 2006.

[16] A. N. Yusoff, M. H. Abdullah, S. H. Ahmad, S. F. Jusoh, A. A. Mansor, and S. A. A. Hamid, "Electromagnetic and absorption properties of some microwave absorbers," Journal of Applied Physics, vol. 92, no. 2, pp. 876-882, 2002.

[17] N. Zhang, Y. Huang, and M. Wang, "3D ferromagnetic graphene nanocomposites with $\mathrm{ZnO}$ nanorods and $\mathrm{Fe}_{3} \mathrm{O}_{4}$ nanoparticles co-decorated for efficient electromagnetic wave absorption," Composites Part B Engineering, vol. 136, pp. 135142,2018

[18] A. S. Hoang, "Electrical conductivity and electromagnetic interference shielding characteristics of multiwalled carbon nanotube filled polyurethane composite films," Advances in Natural Sciences: Nanoscience and Nanotechnology, vol. 2, no. 2, article 025007, 2011.

[19] S. Kuester, G. M. O. Barra, J. C. Ferreira Jr., B. G. Soares, and N. R. Demarquette, "Electromagnetic interference shielding and electrical properties of nanocomposites based on poly (styrene-b-ethylene-ran-butylene-b-styrene) and carbon nanotubes," European Polymer Journal, vol. 77, pp. 43-53, 2016.

[20] S. Sugimoto, T. Maeda, D. Book et al., "GHz microwave absorption of a fine $\alpha$-Fe structure produced by the disproportionation of $\mathrm{Sm}_{2} \mathrm{Fe}_{17}$ in hydrogen," Journal of Alloys Compounds, vol. 330-332, pp. 301-306, 2002.

[21] V. A. Zhuravlev, V. I. Suslyaev, E. Y. Korovin, and K. V. Dorozhkin, "Electromagnetic waves absorbing characteristics of composite material containing carbonyl iron particles," Materials Sciences and Applications, vol. 5, no. 11, pp. 803811, 2014.

[22] A. Ameli, P. U. Jung, and C. B. Park, "Electrical properties and electromagnetic interference shielding effectiveness of polypropylene/carbon fiber composite foams," Carbon, vol. 60, pp. 379-391, 2013.

[23] K. Zhang, X. Gao, Q. Zhang, T. Li, H. Chen, and X. Chen, "Preparation and microwave absorption properties of asphalt carbon coated reduced graphene oxide/magnetic $\mathrm{CoFe}_{2} \mathrm{O}_{4}$ hollow particles modified multi-wall carbon nanotube composites," Journal of Alloys and Compounds, vol. 723, pp. 912921, 2017.

[24] J. Wu, Z. Ye, H. Ge, J. Chen, W. Liu, and Z. Liu, "Modified carbon fiber/magnetic graphene/epoxy composites with synergistic effect for electromagnetic interference shielding over broad frequency band," Journal of Colloid and Interface Science, vol. 506, pp. 217-226, 2017. 


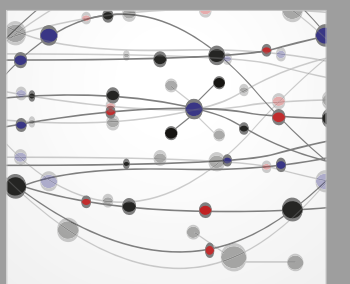

The Scientific World Journal
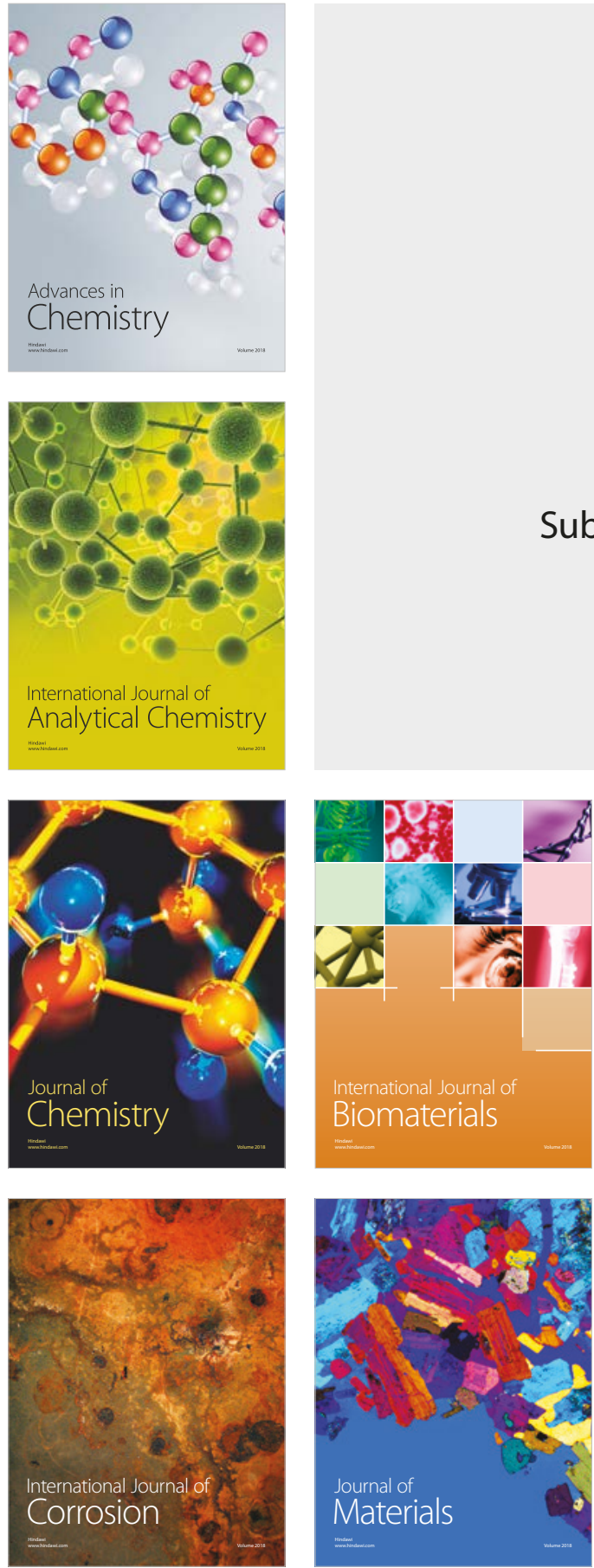

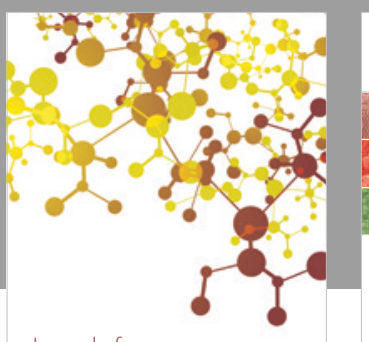

Journal of

Applied Chemistry
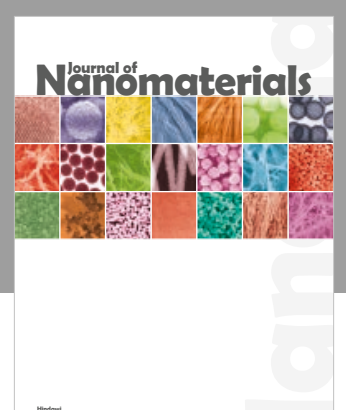

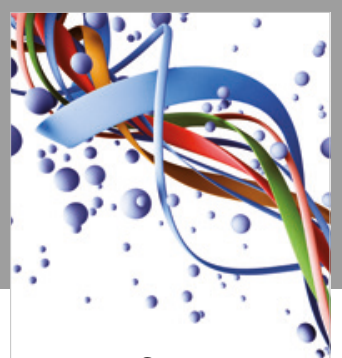

Scientifica

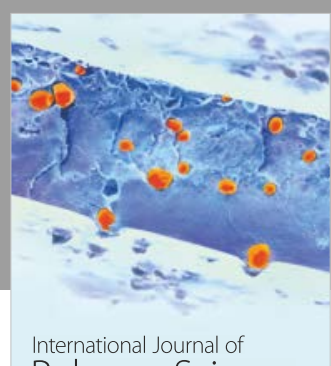

Polymer Science

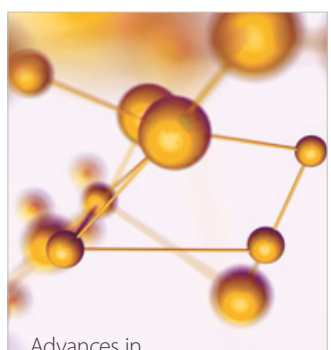

Physical Chemistry
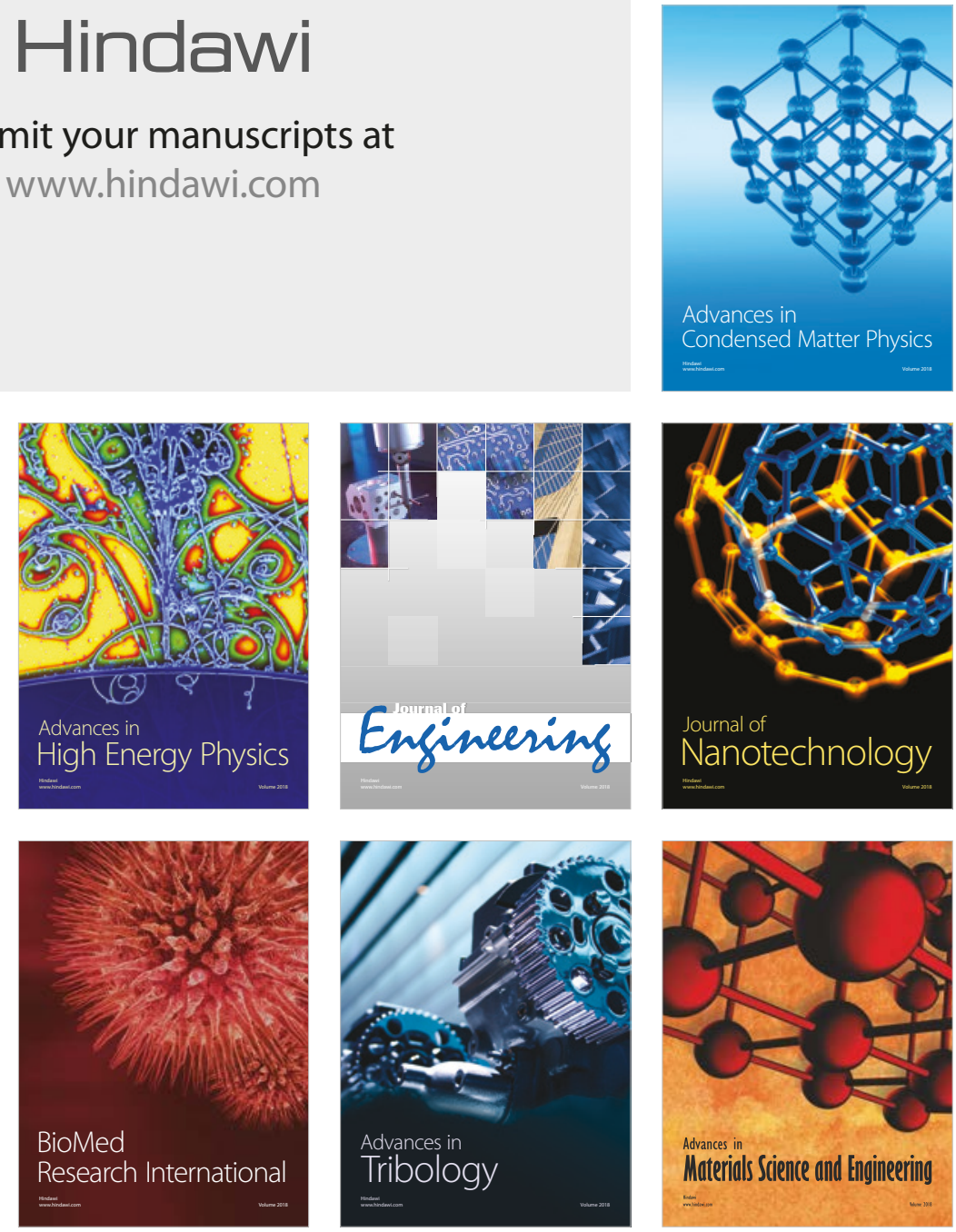